\title{
VELOCIDADE DE SEMEADURA DA SOJA ${ }^{1}$
}

\section{ROBERTO JASPER ${ }^{2}$, MONICA JASPER ${ }^{3}$, PAULO S. M. ASSUMPÇÃO ${ }^{4}$, JORGE ROCIL ${ }^{5}$, LUIZ C. GARCIA ${ }^{6}$}

RESUMO: Teve-se o objetivo de estudar a influência da velocidade da semeadura na cultura da soja, com sistemas dosadores de sementes dos tipos disco alveolado horizontal e pneumático. $\mathrm{O}$ delineamento experimental adotado foi o em blocos ao acaso, com 05 repetições. As velocidades de semeadura foram de $4 ; 6 ; 8 ; 10$ e $12 \mathrm{~km} \mathrm{~h}^{-1}$. As variáveis avaliadas foram: população de plantas emergidas, distribuição longitudinal e os componentes de rendimento. Aplicou-se a regressão polinomial para os sistemas de disco alveolado horizontal e pneumático, em cada variável. As regressões só foram significativas para o sistema pneumático nos espaçamentos múltiplos e aceitáveis. Os componentes de rendimento da cultura da soja não se alteraram significativamente com o incremento da velocidade de semeadura até $12 \mathrm{~km} \mathrm{~h}^{-1}$ para os sistemas dosadores de sementes dos tipos disco alveolado horizontal e pneumático.

PALAVRAS-CHAVE: componentes de rendimento, disco alveolado horizontal e pneumático.

\section{SPEED OF SOWING ON SOYBEAN CROP}

ABSTRACT: The objective was to study the influence of increasing the speed of sowing on the soybean crop, with horizontal seed plate and pneumatic seed distribution systems. The experimental design adopted was randomized block with 5 replicates. The sowing speeds were 4, 6, 8, 10 e $12 \mathrm{~km}$ $\mathrm{h}^{-1}$. The variables were: population of plants emerged, longitudinal distribution and components of yield. It was applied the polynomial regression for horizontal seed plate and pneumatic systems, for each variable. The regressions were significant only for the pneumatic system on longitudinal distribution. The components of soybean crop yield have not changed with the increase of the sowing speed until $12 \mathrm{~km} \mathrm{~h}^{-1}$ in the seed dispensing systems of horizontal and pneumatic plates.

KEYWORDS: components of yield, horizontal and pneumatic plates.

\section{INTRODUÇÃO}

Durante o processo de implantação de uma lavoura no plantio direto, os aspectos mais relevantes para seu sucesso estão relacionados com o desempenho da semeadora-adubadora no que se refere ao corte eficiente dos restos culturais, à abertura do sulco e à correta distribuição de semente e do fertilizante no solo (EMBRAPA, 1994). A desuniformidade na distribuição longitudinal de plantas implica um aproveitamento ineficiente dos recursos disponíveis, como luz, água e nutrientes. Na cultura da soja, o acúmulo de plantas pode provocar o desenvolvimento de plantas de maior porte, porém menos ramificadas, com menor produção individual, diâmetro de haste reduzido e, portanto, mais propensas ao acamamento (ENDRES, 1996).

De acordo com DALLMEYER \& BOLLER (1995), são usados dois tipos de máquinas para semeadura da soja: a semeadora de fluxo contínuo e a de precisão. As de precisão apresentam maior regularidade na distribuição longitudinal das sementes, porém exigem maior atenção nas regulagens e na operação. Para BALASTREIRE (1987), as semeadoras de precisão em uso para a soja podem

\footnotetext{
${ }^{1}$ Financiado pela SOCIDISCO Ltda.

${ }^{2}$ Eng $^{\mathrm{O}}$ Agrônomo, Professor da Universidade Estadual de Ponta Grossa, UEPG, Ponta Grossa - PR, Fone: (0XX42) 3229.5010, jasper@uepg.br.

${ }^{3}$ Eng ${ }^{\text {O }}$ Agrônoma, Mestranda pela Universidade Estadual de Ponta Grossa, UEPG, Ponta Grossa - PR.

${ }^{4}$ Engo Agrônomo, Fazenda Santa Branca, Tibagi - PR.

${ }^{5}$ Eng $^{\mathrm{O}}$ Agrônomo, Fazenda Santa Branca, Tibagi - PR.

${ }^{6}$ Eng $^{\mathrm{o}}$ Agrônomo, Doutor, SOCIDISCO, Ponta Grossa - PR.

Recebido pelo Conselho Editorial em: 12-6-2009
}

Aprovado pelo Conselho Editorial em: 19-12-2010 
ser equipadas com dosadores para sementes do tipo discos alveolados horizontais, inclinados ou verticais, correias perfuradas, dedos prensores, canecas e com dosadores pneumáticos de sucção (vácuo) ou pressão.

Conforme PACHECO et al. (1996), quando as sementes são liberadas do disco alveolado horizontal, adquirem, em queda livre, um componente vertical de velocidade por causa da aceleração da gravidade, e um componente horizontal decorrente da velocidade de avanço da semeadora. O componente horizontal faz com que, normalmente, as sementes rolem ou saltem para fora do local de destino, no momento do impacto com o solo. Além do aumento no componente horizontal de velocidade, o aumento da velocidade de deslocamento propicia um aumento na velocidade tangencial do disco, que apresenta bom desempenho com até $0,29 \mathrm{~m} \mathrm{~s}^{-1}$.

DELAFOSSE (1986) relata que a velocidade na operação de semeadura é um dos parâmetros que mais influencia no desempenho de semeadoras, sendo a distribuição longitudinal de sementes no sulco de semeadura alterada, afetando a produtividade da cultura.

CASÃO JÚNIOR et al. (2000), testando a qualidade de semeadura em soja com discos alveolados horizontais, de 4,5 e $8,0 \mathrm{~km} \mathrm{~h}^{-1}$, apontam erros de deposição das sementes na velocidade de deslocamento de $8,0 \mathrm{~km} \mathrm{~h}^{-1}$. No sistema pneumático, CORTEZ et al. (2006) concluíram que, ao se elevar a velocidade na operação de semeadura no sistema pneumático, reduziu-se significativamente a quantidade de espaçamentos aceitáveis, aumentou-se a quantidade de espaçamentos falhos e não se alterou o estande. REIS et al. (2007), avaliando velocidades de semeadura em soja de 3,8 a $9,5 \mathrm{~km} \mathrm{~h}^{-1}$, com disco alveolado horizontal, concluíram que a velocidade de $7,7 \mathrm{~km} \mathrm{~h}^{-1}$ apresentou maior percentual de falhas. DIAS et al. (2009) concluíram que o aumento de velocidade na semeadura da soja, com distribuição de sementes pelo sistema de disco horizontal alveolado, reduziu significativamente os espaçamentos aceitáveis, mas não interferiu na densidade de sementes.

Entretanto, PORTELLA (1999) afirma que, no sistema pneumático, o desempenho é satisfatório até a velocidade de $10 \mathrm{~km} \mathrm{~h}^{-1}$. REIS \& ALONÇO (2001), comparando a precisão funcional de vários mecanismos dosadores utilizados no Brasil, concluíram que, com velocidades de semeadura acima de $7,5 \mathrm{~km} \mathrm{~h}^{-1}$, a qualidade da distribuição de sementes com mecanismos pneumáticos e disco horizontal alveolado se assemelha. KLEIN et al. (2002) variaram a velocidade de semeadura da soja com sistema de disco alveolado horizontal de 3,6 a $10,8 \mathrm{~km} \mathrm{~h}^{-1}$, concluindo que a elevação da velocidade de semeadura não afetou a qualidade da distribuição longitudinal e o número de plantas emergidas. No sistema de disco alveolado horizontal, a velocidade de semeadura da soja até 7,3 $\mathrm{km} \mathrm{h}^{-1}$ não alterou significativamente o número médio de dias para a emergência das plântulas da cultura da soja, na distribuição longitudinal de sementes e na produtividade da soja (BRANQUINHO et al., 2004).

O objetivo deste experimento foi estudar a influência do incremento da velocidade da semeadura na cultura da soja, com sistemas de disco alveolado horizontal e pneumático.

\section{MATERIAL E MÉTODOS}

A cultura da soja foi implantada na região dos Campos Gerais do Estado do Paraná, $25^{\circ} 16^{\prime}$ de latitude sul e 50 $16^{\prime}$ ' de longitude oeste, clima $\mathrm{Cfb}$, em sistema de plantio direto sob a palha.

Na Fazenda Santa Branca, Município de Tibagi, Latossolo Vermelho distrófico, havia no momento da semeadura $6,6 \mathrm{t} \mathrm{ha}^{-1}$ de palha, manejada quimicamente 01 dia antes da semeadura da soja, que ocorreu em 23 de novembro de 2006. Não houve adubação no momento da semeadura. As 400.000 sementes da variedade COODETEC 206, distribuídas por hectare, tinham 90\% de germinação e $97 \%$ de pureza. Os tratores utilizados foram da mesma marca e potência, John Deere ${ }^{\circledR}$ $7505-140 \mathrm{cv}$.

A semeadora-adubadora com sistema mecânico do tipo disco alveolado horizontal utilizada foi a SSM $27^{\circledR}$, equipada com 13 unidades de semeadura, espaçadas entre si em $0,40 \mathrm{~m}$, com disco 
de 86 orifícios de 7,5 mm, pneu com $3,45 \mathrm{~m}$ de circunferência a campo, relação de engrenagens para sementes 1,20 , disco de corte com 13 ondas e $0,46 \mathrm{~m}$ de diâmetro, mecanismo de abertura do sulco da semente com disco duplo desencontrado de 0,41 $\mathrm{m}$ de diâmetro.

A semeadora-adubadora pneumática empregada foi a SLC $913^{\circledR}$, equipada com 13 unidades de semeadura, espaçadas entre si em $0,40 \mathrm{~m}$, com disco de 30 orifícios, pressão de $0,8 \mathrm{MPa}$, pneu com 2,80 m de circunferência a campo, relação de engrenagens para sementes 1,44 , disco de corte com 13 ondas e $0,46 \mathrm{~m}$ de diâmetro, mecanismo de abertura do sulco da semente com disco duplo desencontrado de $0,41 \mathrm{~m}$.

Todas as semeadoras foram reguladas para que a semente fosse distribuída a $0,03 \mathrm{~m}$ de profundidade, sem fertilizante na semeadura. $\mathrm{O}$ fechamento do sulco de todas as semeadoras era do tipo roda duplo-angulada em "V" de $0,31 \mathrm{~m}$ de diâmetro. Os depósitos de sementes foram abastecidos a $50 \%$ de sua capacidade. O teor médio de água no solo, na camada de 0,0 a $0,1 \mathrm{~m}$, foi de $32 \%$.

Na propriedade, o delineamento experimental foi em blocos casualizados, nas velocidades de deslocamento de $4 ; 6 ; 8 ; 10$ e $12 \mathrm{~km} \mathrm{~h}^{-1}$. Foram cinco repetições por tratamento. As parcelas tinham $30 \mathrm{~m}$ de comprimento por $6 \mathrm{~m}$ de largura, para permitir a aceleração e desaceleração do tracionador. As velocidades foram alcançadas com o escalonamento de marcha e aceleração aferidas com o auxílio de um GPS marca Garmin ${ }^{\circledR}$, modelo Etrex ${ }^{\circledR}$.

As variáveis avaliadas 20 dias após a emergência foram população inicial e distribuição longitudinal (espaçamentos falhos, múltiplos e aceitáveis). Na colheita, registraram-se a população final, número de vagens por planta, grãos por vagem, massa de mil grãos e produtividade. $\mathrm{O}$ tamanho da amostra levou em consideração a estabilização da média e do desvio-padrão das variáveis analisadas, conforme método proposto por KRANZ (1988), ficando em $10 \mathrm{~m}^{2}$.

A distribuição longitudinal deu-se pela análise dos espaçamentos entre as plantas. As avaliações foram embasadas nas recomendações da Associação Brasileira de Normas Técnicas (1996), que considera como aceitáveis todos os espaçamentos entre plantas de 0,5 e 1,5 vez o espaçamento médio (EM) esperado. Os valores obtidos fora desse limite foram considerados como espaçamentos falhos (acima de 1,5 vez EM) ou múltiplos (abaixo de 0,5 vez EM).

A colheita, contagem de vagem por planta, grãos por vagem, massa de mil grãos e debulha foram realizados manualmente. A massa de mil grãos e a produtividade tiveram seus valores corrigidos para $13 \%$ de umidade.

Aplicou-se o teste de Hartley para verificação da homocedasticidade das variâncias. Os valores levantados foram submetidos à análise estatística, empregando-se os testes " $F$ " e regressão polinomial.

\section{RESULTADOS E DISCUSSÃO}

Todas as variâncias apresentaram homocedasticidade pelo teste de Hartley, dispensando a transformação dos dados para a análise de variância. O teste $\mathrm{F}$ não indicou diferenças significativas para os blocos, denotando a homogeneidade da área utilizada para o experimento.

A regressão não apontou diferenças significativas na população inicial (Figura 1) e espaçamentos falhos (Figura 2) entre plantas de soja com o incremento da velocidade do conjunto trator-semeadora, para os dois sistemas de distribuição investigados. Assim, contrariam-se as conclusões de CASÃO JÚNIOR et al. (2000) e REIS et al. (2007). Contudo, ratificam-se as afirmações de PORTELLA (1999), REIS \& ALONÇO (2001), KLEIN et al. (2002) e BRANQUINHO et al. (2004).

Como CORTEZ et al. (2006) e DIAS et al. (2009) asseguraram que a densidade não foi afetada significativamente com o aumento da velocidade de semeadura da soja, mas os 
espaçamentos falhos sim, o presente trabalho corrobora as afirmações sobre a densidade e contesta as conclusões referentes à distribuição.

As velocidades tangenciais nos deslocamentos de $4 ; 6 ; 8 ; 10$ e $12 \mathrm{~km} \mathrm{~h}^{-1}$ foram, respectivamente, 0,$12 ; 0,18 ; 0,24 ; 0,31$ e $0,37 \mathrm{~m} \mathrm{~s}^{-1}$ no sistema de disco alveolado horizontal e 0,48 ; 0,$72 ; 0,96 ; 1,21$ e $1,45 \mathrm{~m} \mathrm{~s}^{-1}$ no sistema pneumático. Portanto, mesmo ambos os sistemas trabalhando acima do limite de $0,29 \mathrm{~m} \mathrm{~s}^{-1}$, considerado como aceitável por PACHECO et al. (1996), não houve influência significativa na população inicial e porcentagem de espaçamentos falhos com o incremento da velocidade tangencial do disco de distribuição de sementes.
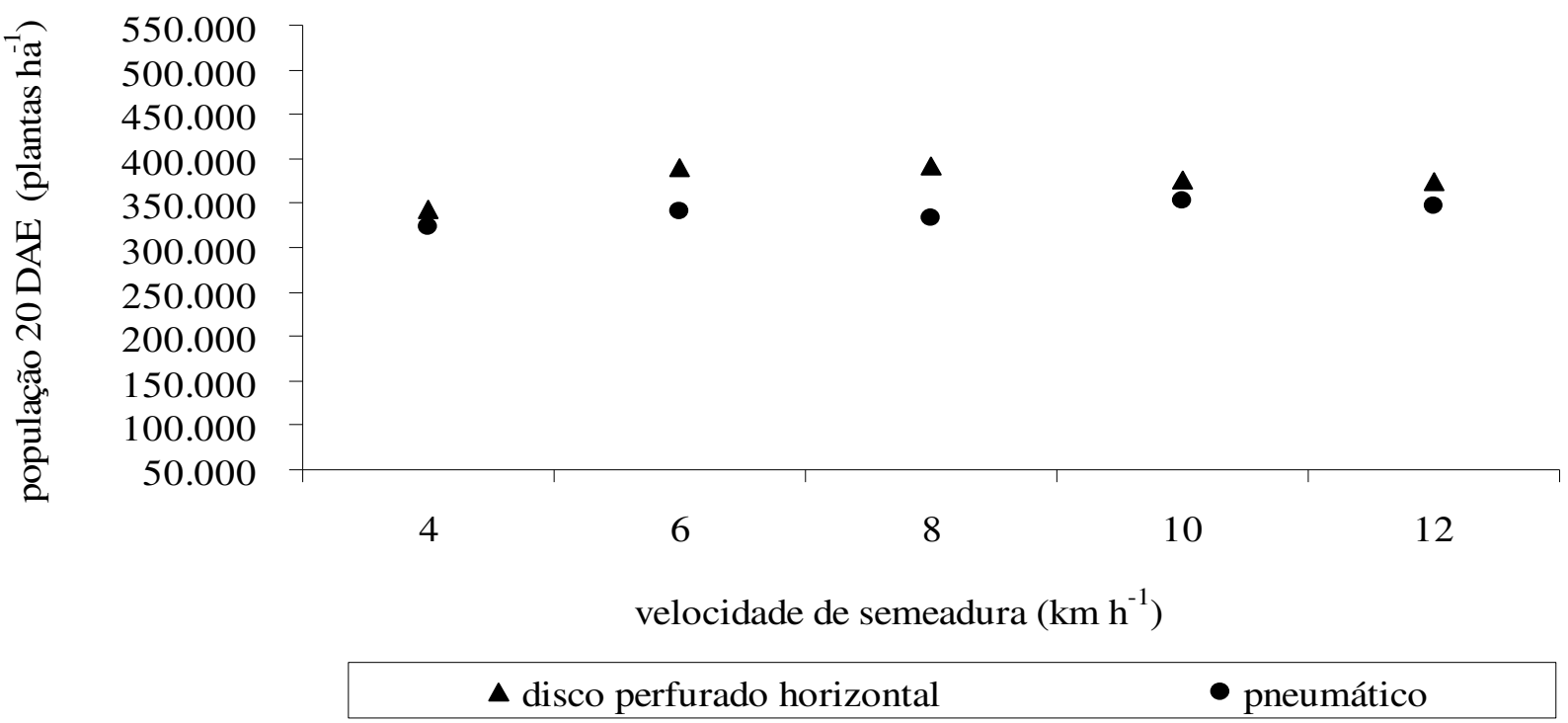

FIGURA 1. População de soja 20 dias após a emergência (DAE), com velocidade crescente de semeadura, em dois sistemas de distribuição: disco alveolado horizontal e pneumático (TIBAGI - PR). Soybean population 20 days after emergence (DAE) with increasing speeds of sowing, in two distribution systems, horizontal and pneumatic plates (Tibagi - PR).

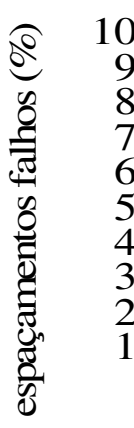

100
90
80
70
60
50
40
30
20
10
0

$\begin{array}{r}100 \\ 90 \\ 80 \\ 70 \\ 60 \\ 50 \\ 40 \\ 30 \\ 20 \\ 10 \\ 0\end{array}--$

6

8

10

12

velocidade de semeadura $\left(\mathrm{km} \mathrm{h}^{-1}\right)$

A disco perfurado horizontal

- pneumático

FIGURA 2. Espaçamentos falhos, com velocidade crescente de semeadura da soja, em dois sistemas de distribuição: disco alveolado horizontal e pneumático (TIBAGI - PR).

Failing spacing with increasing speeds of sowing, in two distribution systems, horizontal and pneumatic plates (Tibagi - PR).

Ao se estudar a influência da velocidade de semeadura nos espaçamentos múltiplos (Figura 3) e aceitáveis (Figura 4), verificou-se que a distribuição das sementes pelo sistema de disco alveolado horizontal não foi afetada. Os resultados contestam as conclusões de CASÃO JÚNIOR et al. 
(2000), REIS et al. (2007) e DIAS et al. (2009); entretanto, corroboram as afirmações de KLEIN et al. (2002) e BRANQUINHO et al., (2004).

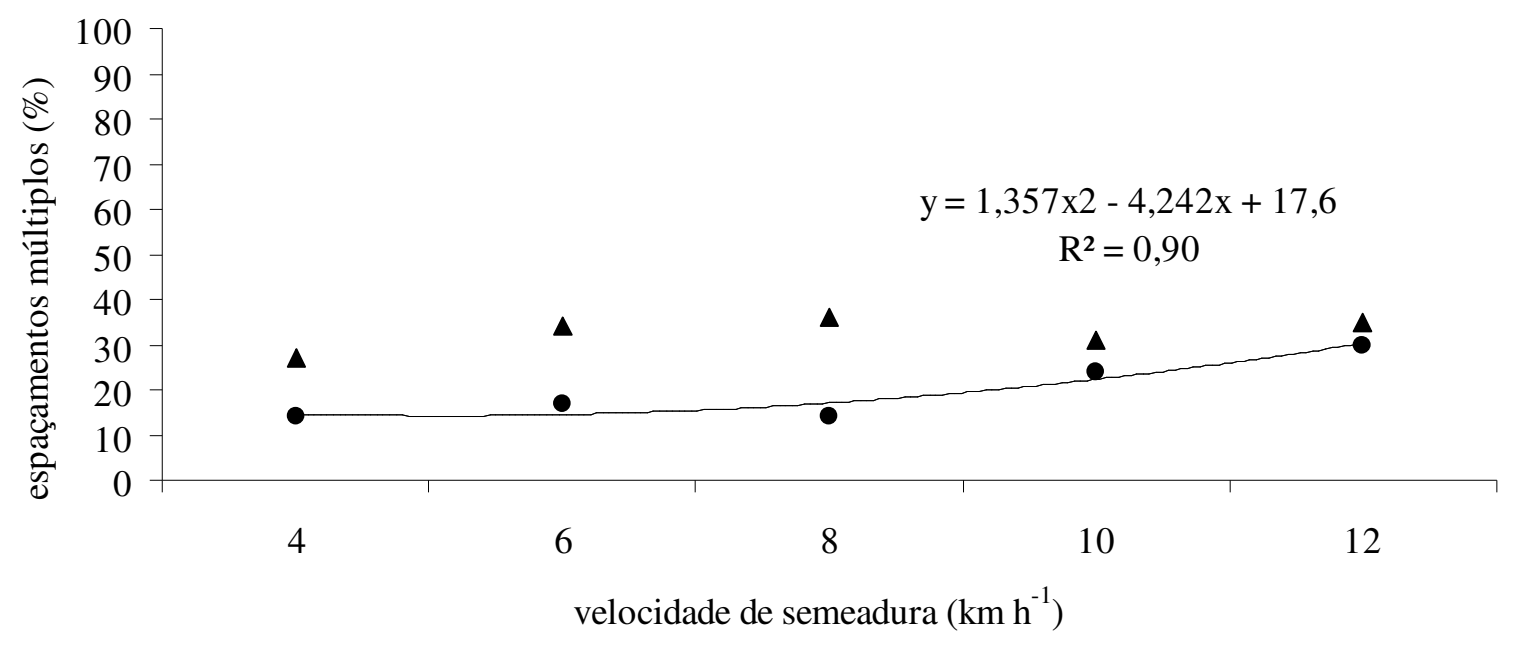

$\Delta$ disco perfurado horizontal

- pneumático

FIGURA 3. Espaçamentos múltiplos, com velocidade crescente de semeadura da soja, em dois sistemas de distribuição: disco alveolado horizontal e pneumático (TIBAGI - PR). Multiple spacing with increasing speeds of sowing, in two distribution systems, horizontal and pneumatic plates (Tibagi - PR).

Já no sistema pneumático, houve aumento nos espaçamentos múltiplos e redução dos espaçamentos aceitáveis. Assim, confirmam-se as avaliações de CORTEZ et al. (2006).

Mesmo com a redução significativa nos espaçamentos aceitáveis de plântulas ao se elevar a velocidade de semeadura, o sistema pneumático apresentou valores inferiores de espaçamentos múltiplos e maior porcentagem de espaçamentos aceitáveis em comparação ao sistema de disco alveolado horizontal. Portanto, a distribuição longitudinal de sementes foi melhor no sistema pneumático, em comparação ao sistema de disco alveolado horizontal, quando do incremento da velocidade. Resultados que ratificam as conclusões de PORTELLA (1999).

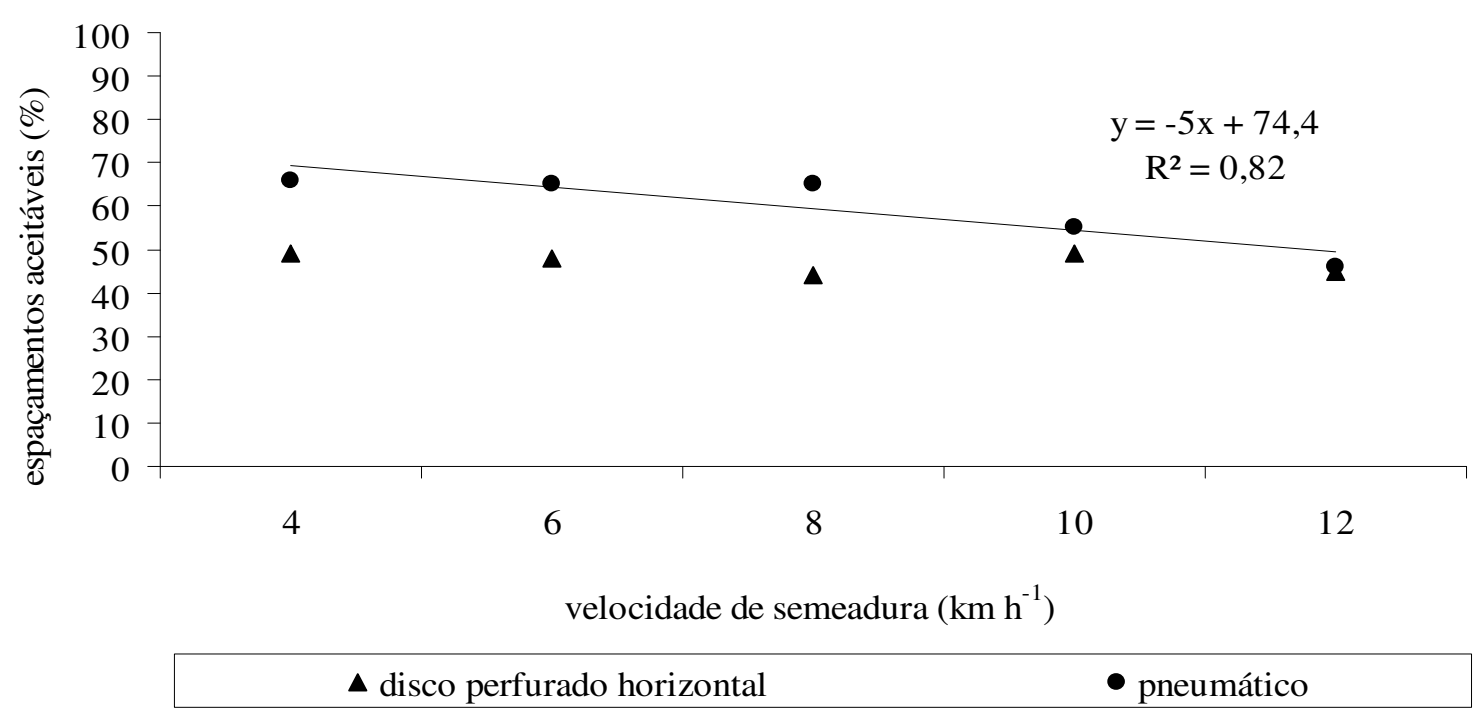

FIGURA 4. Espaçamentos aceitáveis, com velocidade crescente de semeadura da soja, em dois sistemas de distribuição: disco alveolado horizontal e pneumático (TIBAGI - PR). Acceptable spacing with increasing speeds of sowing, in two distribution systems, horizontal and pneumatic plates (Tibagi - PR). 
A regressão polinomial não apontou diferenças significância para os componentes de rendimento da soja (Figuras 5; 6; 7; 8 e 9) com o incremento da velocidade do conjunto trator-semeadora, para os dois sistemas de distribuição de sementes analisados, disco alveolado horizontal e pneumático. Dessa forma, contrariam-se as conclusões de DELAFOSSE (1986) e confirmam-se as afirmações de PORTELLA (1999), REIS \& ALONÇO (2001) e BRANQUINHO et al. (2004).

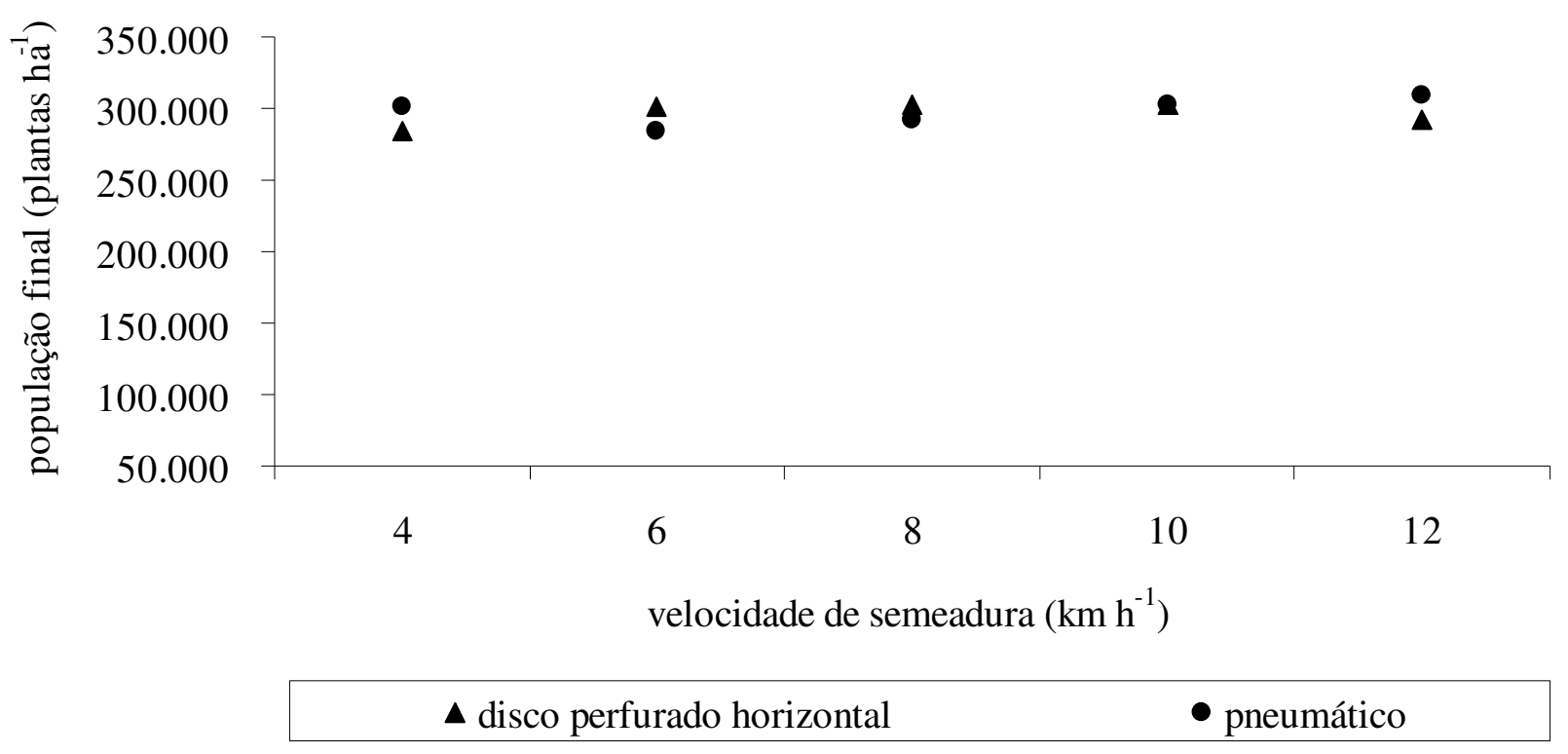

FIGURA 5. População final de soja, com velocidade crescente de semeadura, em dois sistemas de distribuição: disco alveolado horizontal e pneumático (TIBAGI - PR). Final population with increasing speeds of sowing, in two distribution systems, horizontal and pneumatic plates (Tibagi - PR).

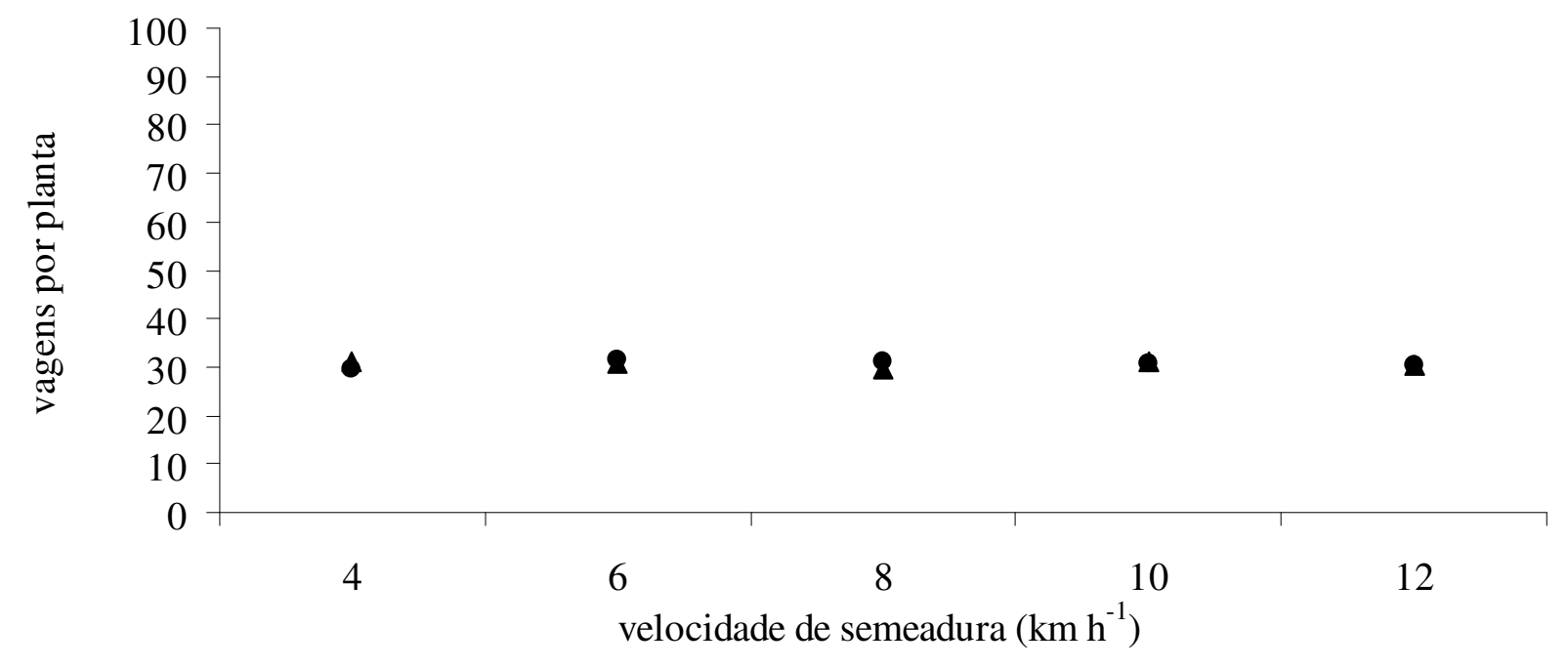

$\Delta$ disco perfurado horizontal $\quad$ pneumático

FIGURA 6. Vagens por planta, com velocidade crescente de semeadura da soja, em dois sistemas de distribuição: disco alveolado horizontal e pneumático (TIBAGI - PR). Pods per plant with increasing speeds of sowing, in two distribution systems, horizontal and pneumatic plates (Tibagi - PR). 


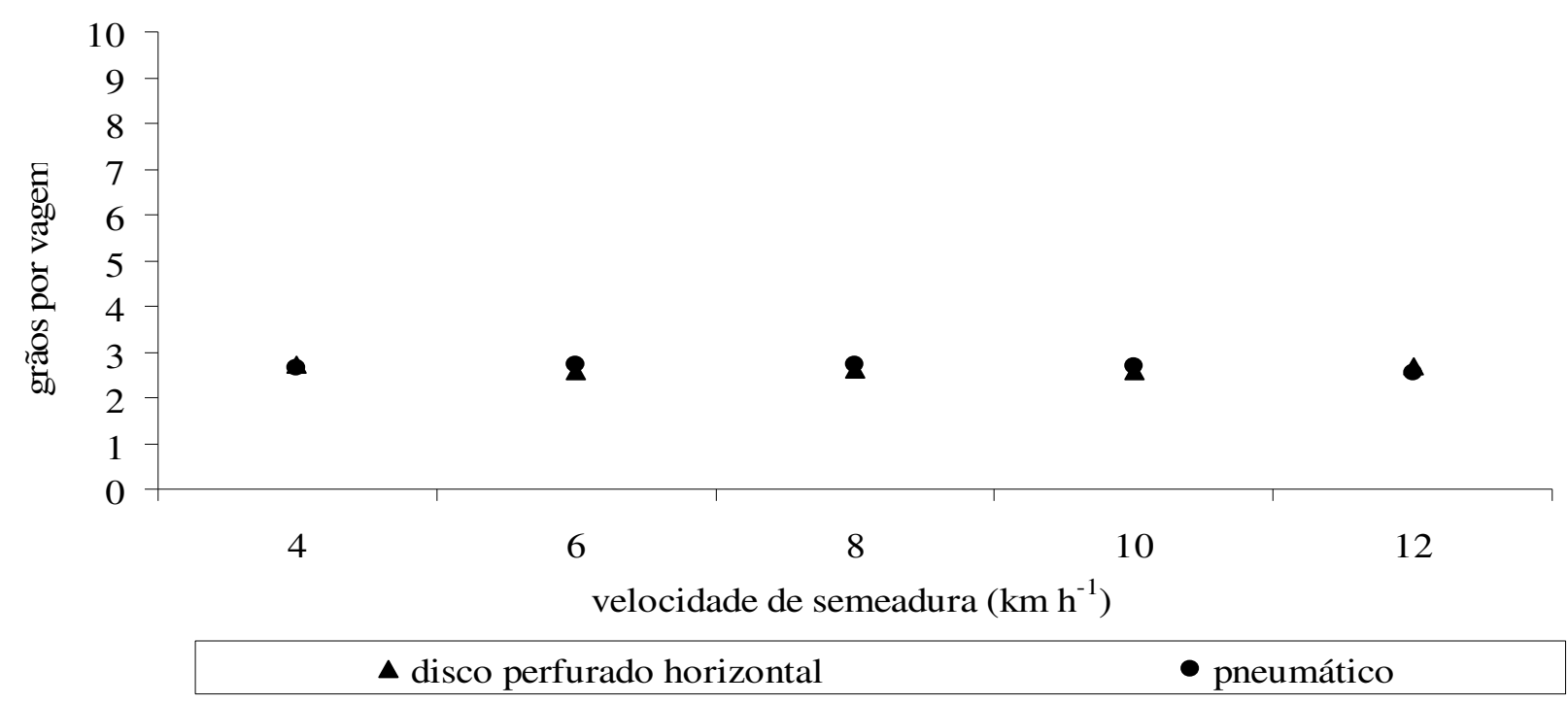

FIGURA 7. Grãos por vagem, com velocidade crescente de semeadura da soja, em dois sistemas de distribuição: disco alveolado horizontal e pneumático (TIBAGI - PR). Number of grains per pod with increasing speeds of sowing, in two distribution systems, horizontal seed plate and pneumatic (Tibagi - PR).

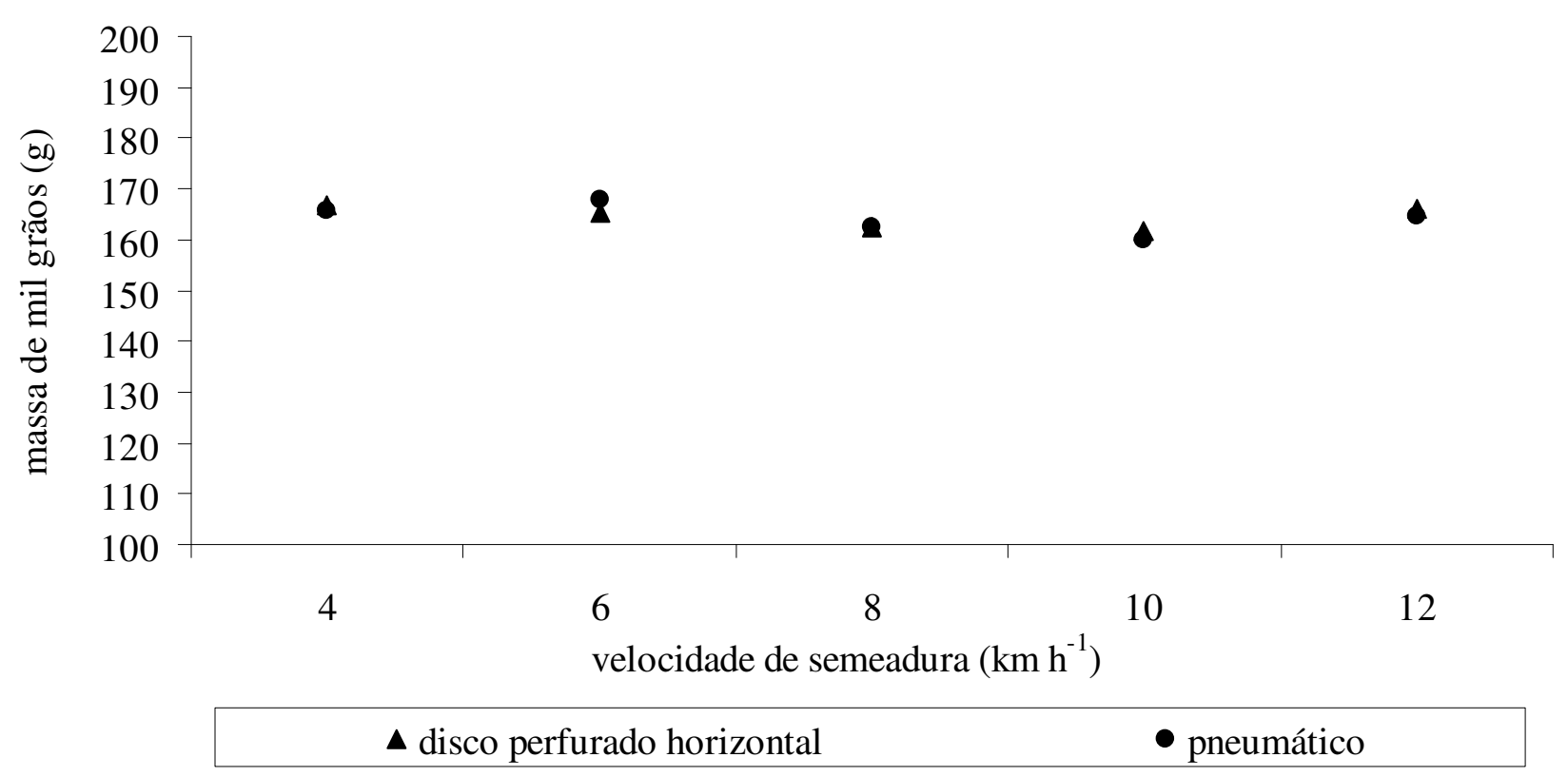

FIGURA 8. Massa de mil grãos, com velocidade crescente de semeadura da soja, em dois sistemas de distribuição: disco alveolado horizontal e pneumático (TIBAGI - PR). Weight of hundred grains with increasing speeds of sowing, in two distribution systems, horizontal and pneumatic plates (Tibagi - PR). 


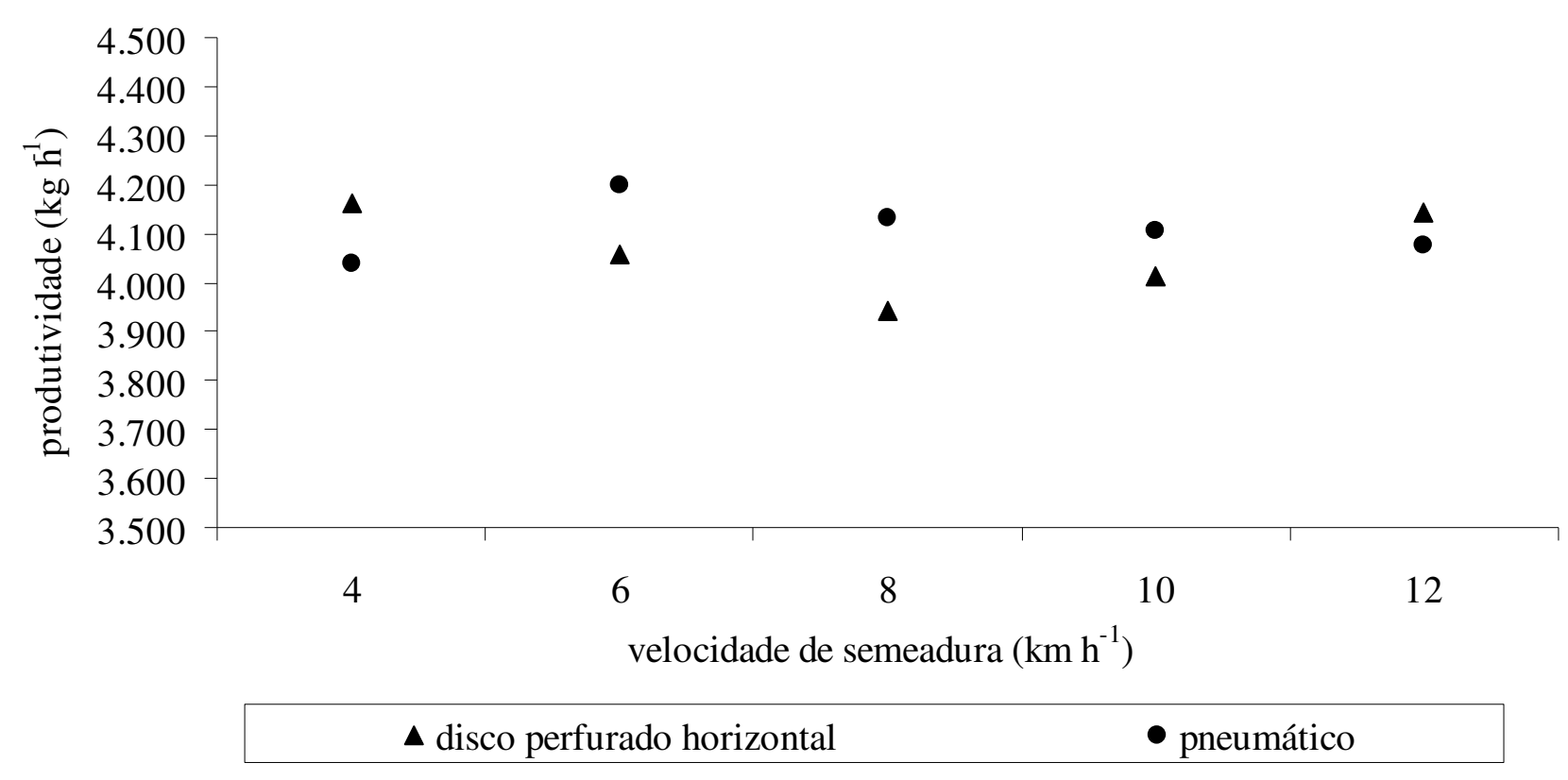

FIGURA 9. Produtividade da soja, com velocidade crescente de semeadura, em dois sistemas de distribuição: disco alveolado horizontal e pneumático (TIBAGI - PR). Soybean productivity with increasing speeds of sowing, in two distribution systems, horizontal and pneumatic plates (Tibagi - PR).

\section{CONCLUSÕES}

Com aumento da velocidade de semeadura de soja, houve diferenças significativas na distribuição longitudinal para o sistema pneumático, nas variáveis espaçamentos múltiplos e aceitáveis. Assim, concluiu-se que, ao se elevar a velocidade de semeadura, há aumento de espaçamentos múltiplos e redução dos aceitáveis.

Os componentes de rendimento não se alteraram nos sistemas de disco alveolado horizontal e pneumático com o incremento da velocidade de semeadura até $12 \mathrm{~km} \mathrm{~h}^{-1}$.

\section{REFERÊNCIAS}

ABNT. ASSOCIAÇÃO BRASILEIRA DE NORMAS TÉCNICAS. Projeto de norma 04:015.06004/1995. Semeadora de precisão: ensaio de laboratório/método de ensaio. São Paulo: ABNT, 1996. $21 \mathrm{p}$.

BALASTREIRE, L.A. Máquinas agrícolas. São Paulo: Manole, 1987. 307 p.

BRANQUINHO, K.B.; FURLANI, C.E.A.; LOPES, A.; SILVA, R.P.; GROTTA, D.C.C.;

BORSATTO, E.A. Desempenho de uma semeadora-adubadora direta, em função da velocidade de deslocamento e do tipo de manejo da biomassa da cultura de cobertura do solo. Engenharia Agrícola, Jaboticabal, v.24, n.2, p.374-380, 2004.

CASÃO JUNIOR, R.; ARAUJO, A.G.; RALISCH, R. Desempenho da semeadora-adubadora MAGNUM 2850 em plantio direto no basalto paranaense. Pesquisa Agropecuária Brasileira, Brasília, v.35, n.3, p.523-532, 2000.

CORTEZ, J.W.; FURLANI, C.E.A.; SILVA, R.P.; LOPES, A. Distribuição longitudinal de sementes de soja e características físicas do solo no plantio direto. Engenharia Agrícola, Jaboticabal, v.26, n.2, p.502-510, 2006.

DALLMEYER, A.U.; BOLLER, W. Máquinas para a cultura da soja. In: O.S., (Org.). A cultura da soja. 2.ed. Rio de Janeiro: Globo, 1995. p.213-244. 
DELAFOSSE, R.M. Máquinas semeadoras de grano grueso. Santiago: FAO, 1986. 48 p.

DIAS, O.V.; ALONÇO, A.S.; BAUMHARDT, U.B.; BONOTTO, J.G. Distribuição de sementes de milho e soja em função da velocidade e densidade de semeadura. Ciência Rural, Santa Maria, v.39, n.6, p.1.721-1.728, 2009.

EMBRAPA. EMPRESA BRASILEIRA DE PESQUISA AGROPECUÁRIA. Avaliação do desempenho de plantadoras diretas para culturas de verão. Passo Fundo: Centro Nacional de Pesquisa de Trigo, 1994.

ENDRES, V.C. Espaçamento, densidade e época de semeadura. In: EMBRAPA. Centro de Pesquisa Agropecuária do Oeste. Soja: recomendações técnicas para Mato Grosso do Sul e Mato Grosso. Dourados, 1996. p.82-85. (Circular Técnica, 3).

KLEIN, V.A.; SIOTA, T.A.; ANESI, A.L.; BARBOSA, R. Efeito da velocidade na semeadura direta de soja. Engenharia Agrícola, Jaboticabal, v.22, n.1, p.75-82, 2002.

KRANZ, J. Measuring plant disease. In KRANZ, J.; ROTEM, J. (Ed.). Experimental techniques in plant disease epidemiology. Heidelberg: Springer, 1988. p.35-50.

PACHECO, E.P.; MANTOVANI, E.C.; MARTYN, P.J.; OLIVEIRA, A. C. Avaliação de uma semeadora-adubadora de precisão. Pesquisa Agropecuária Brasileira, Brasília, v.31, n.3, p.209214, 1996.

PORTELLA, J.A. Plantio de precisão: o desafio para o século XXI. Passo Fundo: Embrapa Trigo, 1999. 2p. (Comunicado Técnico, 25).

REIS, A.V.; ALONÇO, A.S. Comparativo sobre a precisão funcional de vários mecanismos dosadores estudados no Brasil entre os anos de 1989 e 2000. In: CONGRESSO BRASILEIRO DE ENGENHARIA AGRICOLA, 30., 2001, Foz do Iguaçu. Anais... Foz do Iguaçu: Associação Brasileira de Engenharia Agrícola, 2001. 1 CD-ROM.

REIS, E.F.; MOURA, J.R.; DELMOND, J.G.; CUNHA, J.P.A.R. Características operacionais de uma semeadora-adubadora de plantio direto na cultura da soja (Glycine max (L.) Merril). Revista Ciências Técnicas Agropecuárias, Habana, v.16, n.3, p.70-75, 2007. 